Área de Publicação: COMPUTAÇÃO

\title{
A QUALIFICAÇÃO PROFISSIONAL NO PROJOVEM URBANO: EXPECTATIVAS E DESAFIOS DOS JOVENS DA CIDADE DE SANTA INÊS
}

\section{RESUMO}

Este artigo apresenta resultados de uma investigação cujo objetivo foi analisar a influência da Qualificação Profissional na vida dos alunos do Projovem Urbano da cidade de Santa Inês. O programa tem uma proposta de integração curricular envolvendo três dimensões: formação básica, qualificação profissional e participação cidadã. investigamos a influência da disciplina de QP na vida dos jovens, quais foram os principais desafios e as expectativas do aluno do programa durante o período de dezoito meses do Projovem Urbano. Ressaltou-se a importância dos conteúdos trabalhados nos Guias de Estudo de Formação Técnica Geral e de Formação Técnica Específica com o Arco Ocupacional de Telemática. Direcionamos a nossa pesquisa para um estudo de caso, onde os dados foram coletados a partir de questionários aplicados aos alunos na sala de aula. Os resultados do estudo demonstram que a componente é um dos grandes atrativos do programa, criando novas perspectivas para os jovens no mercado de trabalho.

\section{Palavras-Chave: Qualificação Profissional, Projovem Urbano, Santa Inês.}

\section{INTRODUÇÃO}

Este artigo apresenta resultados de uma investigação cujo objetivo foi analisar a influência da Qualificação Profissional na vida dos alunos do Projovem Urbano, por meio de uma efetiva associação entre: elevação da escolaridade, tendo em vista a conclusão do ensino fundamental e a Qualificação Profissional com certificação de formação inicial dos jovens no âmbito do programa.

O Programa foi desenvolvido para jovens que não concluíram o ensino fundamental e possuem idade entre 18 a 29 anos. Em suma, volta-se aos de muito baixa escolaridade, além de ofertar o ensino básico, o programa também dispõe da Qualificação Profissional, ou seja, formação inicial profissional do jovem com o arco ocupacional Telemática.

De acordo com Projeto Político Integrado (PPI) do ProJovem Urbano, o que faz um programa inovador baseado em novas perspectivas de formação, é a integração entre: Conclusão do ensino fundamental, Qualificação Profissional inicial e experiências de participação cidadã, como base para o alcance da finalidade pretendida (PPI, 2008, p. 15).

Portanto, o objetivo é destacar a importância no âmbito da qualificação profissional, para os jovens da Escola Enéas Leite na cidade de Santa Inês, analisando o 


\section{Encontro de Educação, Ciência e Tecnologia}

26 a 28 de Março de 2018 - UEPB - Campina Grande, PB

crescimento pessoal, profissional e visão crítica da realidade onde vive. Além de analisar as competências desenvolvidas e aquelas destacadas pelos jovens como fundamentais para ocupações geradoras de renda.

\section{METODOLOGIA}

Com a finalidade de alcançar os objetivos desta pesquisa, o trabalho ocorreu de forma teórica, com abordagem quantitativa, através de aplicação de questionários disponibilizado para os educadores do programa Projovem Urbano, para aplicação junto aos alunos do referido programa.

Os educadores organizaram uma roda de conversa, a fim de dialogarem sobre a melhor forma de aplicar os questionários disponibilizados. Levando em consideração, o ambiente propício, os horários e a disponibilidades dos atores envolvidos.

Sendo de fundamental importância a orientação da referência das categorias referentes ao Programa e da escala numérica de variação de 1 a 10, que estará considerando a seguinte escala de valores.

A coleta de dados para análise e desenvolvimento da pesquisa, aconteceu no ambiente escolar da Escola Enéas Leite, na cidade de Santa Inês PB.

Gil (2008) afirma que para interpretar os resultados, o pesquisador precisa ir além da leitura dos dados. Para ele, os dados devem ser integrados em um universo mais amplo, para que se possa fazer algum sentido. Esse universo seria o dos fundamentos teóricos da pesquisa e o dos conhecimentos já acumulados em torno das questões abordadas.

O procedimento de análise executado neste estudo utilizou-se dos critérios quantitativos. Sendo assim, os procedimentos orientadores da análise foram elaborados levando em consideração um conjunto de princípios de Newson \& Newson, 1976, que foram:

a) Coleta dos dados;

b) Processamento dos dados através de tabelas ou gráficos;

c) Análise dos resultados obtidos através do processamento;

d) Interpretação dos dados para elaboração das discussões e conclusões sobre os benefícios da Qualificação Profissional na vida dos jovens. Seja no âmbito educacional ou profissional.

\section{RESULTADOS E DISCUSSÃO}

Nesta seção apresentam-se os dados da pesquisa de campo aplicada com 79 alunos da Escola Enéas Leite na Cidade de Santa Inês - PB, no ano de 2016

Para se compreender uma política voltada para a juventude é necessário compreendê-la como uma categoria. Groppo (2000) observa que a sociedade moderna não é constituída apenas sobre as estruturas de classe, mas também sobre as faixas etárias e gêneros.

Com isso trazemos para vocês os resultados que foram obtidos através de uma pesquisa por meio da aplicação de questionário, onde de inicio iremos discorrer sobre o gênero, destacando o percentual de $58 \%$ para jovens do sexo masculino e $42 \%$ do sexo feminino. Conforme ilustração do gráfico 1. 


\section{Encontro de Educação, Ciência e Tecnologia}

26 a 28 de Março de 2018 - UEPB - Campina Grande, PB

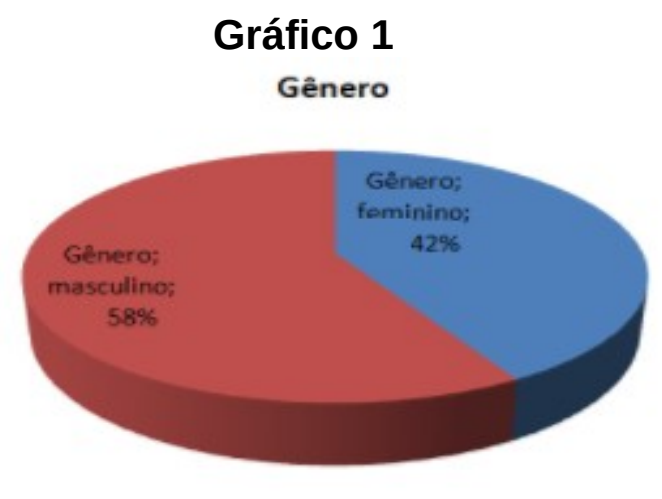

Total de Jovens entrevistados: 79

Fonte: Autoria própria (2017)

No gráfico 2 corresponde a etnia dos alunos entrevistados, foi possível observar que o núcleo era composto por sua maioria por alunos pardos, atingindo um percentual de $61 \%$, o que corresponde a 48 num total de 79 jovens participantes, brancos $23 \%$ e negros $16 \%$, outras etnias não foram citadas.

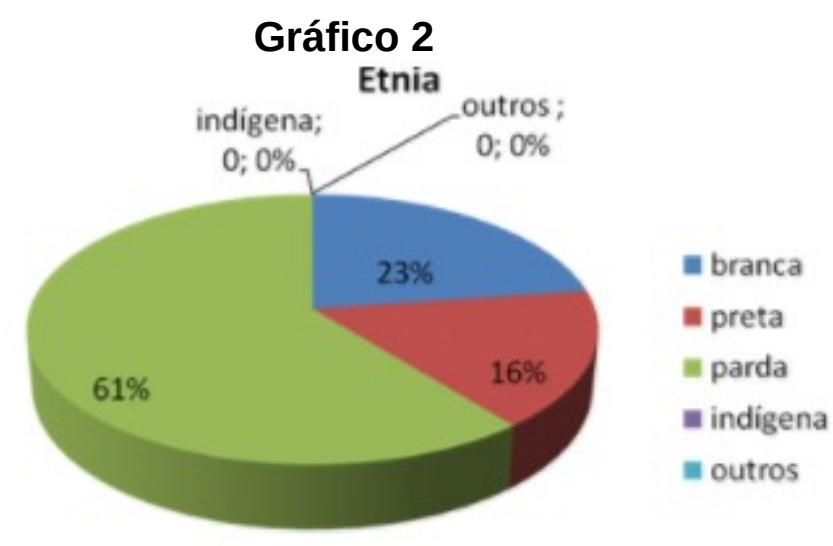

Total de Jovens entrevistados: 79

\section{Fonte: Autoria própria (2017)}

O gráfico 3 vislumbra o quantitativo de alunos com filhos, sendo possível observar que mais da metades deles, precisamente $57 \%$ já tiveram filhos. Sendo este, um dos principais motivos para o abandono escolar, conforme relatos da maioria dos jovens participantes do programa.

\section{Gráfico 3}




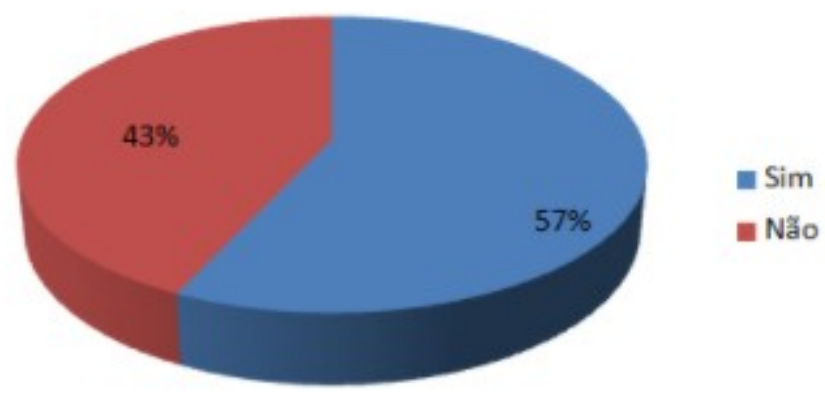

\section{Fonte: Autoria própria (2017)}

É necessário analisar por que essa lógica se insere dentro da educação profissional no ProJovem urbano, avaliando como os ensino é repassado pelos profissionais a esses jovens dentro desse segmento, até por que essa educação, além de uma formação de Qualificação Profissional, subtende-se que esses jovens ao término do programa esteja preparado para o mercado de trabalho. Portanto é importante observar não somente o caráter educativo, mas, principalmente o de formação profissional. Essa análise permite discorrer o que os nossos alunos opinaram a respeito da Qualificação Profissional através do gráfico 4, que diz o seguinte: $47 \%$ acharam excelente, $47 \%$ acharam bom e insatisfatório e apenas $6 \%$ regular, necessita melhorar não foi citado.

\section{Gráfico 4}

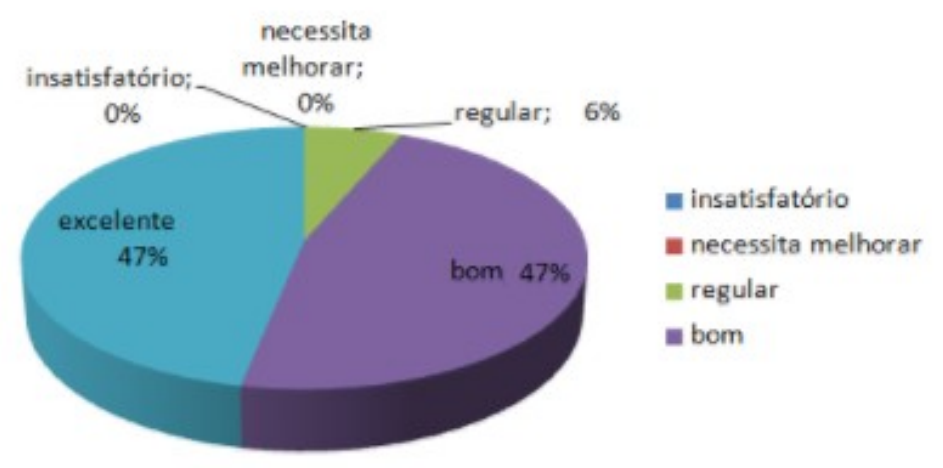

Fonte: Autoria própria (2017)

É de grande relevância os dados levantados, isso mostra que o desenvolvimento das políticas voltadas à juventude e a ampliação do ProJovem significa aproximar o jovem do mercado de trabalho, o objetivo geral do ProJovem Urbano, ao integrar Ensino Fundamental e Qualificação Profissional, é oferecer aos concluintes do programa, a oportunidade de experimentar novas formas de aquisição do conhecimento para inserção social e profissional

\section{CONSIDERAÇÕES FINAIS}




\section{Encontro de Educação, Ciência e Tecnologia}

26 a 28 de Março de 2018 - UEPB - Campina Grande, PB

A qualificação profissional proposta pelo ProJovem deve possibilitar, novas formas de inserção produtiva, com a devida certificação, adaptar-se, na medida do possível, tanto às necessidades e capacidades econômicas. A escola é o lugar de aprender a interpretar o mundo para poder transformá-lo, a partir do domínio das categorias de método e de conteúdo que inspirem e que se transformem em práticas de emancipação humana em uma sociedade cada vez mais mediada pelo conhecimento (KUENZER, 2001).

Através da análise dos dados, foi possível analisar a importância do programa Projovem Urbano na mudança significativa na vida da maioria dos jovens, proporcionando amadurecimento pessoal, educacional e principalmente no contexto profissional com o Arco Telemática, por meio da disciplina de Qualificação Profissional.

Não obstante, os alunos estão motivados com o desejo de adquirir novos conhecimentos e busca contínua por melhor qualidade de vida por meio da educação e incentivos do Programa Projovem Urbano.

\section{REFERÊNCIAS}

BRASIL. (2008) Projeto Pedagógico Integrado - PPI ProJovem Urbano, Brasília: Secretaria Nacional da Juventude.

GIL, Antonio, Carlos. Métodos e técnicas de pesquisa Social. 5. ed. São Paulo: Atlas, 1999.

GROPPO, Luís Antonio. Juventude: ensaios sobre sociologia e história das juventudes modernas. Rio de Janeiro: DIFEL, 2000. 308p.

KUENZER, Acácia Z. As mudanças no mundo do trabalho e a educação: Novos desafios para a gestão. In: FERREIRA, Naura. Gestão democrática da educação: Atuais tendências, novos desafios. São Paulo. Ed. Cortez, 1998.

MARCONI, Marina de Andrade; LAKATOS, Eva Maria. Técnicas de pesquisa. Ed. Atlas. $6^{a}$ edição. São Paulo. 2007. 